\title{
ROLE OF HYSTEROSCOPY IN DIAGNOSIS OF MENSTRUAL DISORDERS
}

\author{
Lt Col BK TANEJA*, Brig RP ARORA+, \\ Col M ALAM\# \\ (Department of Obstetrics \& Gyn, Command Hospital (Southem Command) Pune and Sonawane Maternity Haspital, Pune).
}

\begin{abstract}
Hysteroscopic evaluation was carried out in 120 cases of menstrual disorders with no clinical positive findings. The ages of patients ranged from 20 years to 48 years. Abnormal findings on hysteroscopy were noted in 48.3 percent (58 cases) and histologically abnormal lesions were observed in 35.8 percent (43 cases). Histological correlation with hysteroscopy was $\mathbf{7 4 . 1}$ percent. Lesions like submucous fibroid, polyps, and uterine synechiae were diagnosed with 100 percent accuracy. This study suggests that hysteroscopic evaluation increases the diagnostic precision in patients with intra-uterine lesions and should be done in cases of menstrual disorders alongwith other traditional methods of evaluation.
\end{abstract}

MJAFI 1996; 52 : 15-18

KEY WORDS : Hysteroscopy; Menstrual disorders.

\section{Introduction}

D uring recent years hysteroscopy has generated a lot of interest among gynaecologists, who have always been inquisitive to see the interior of the uterine cavity. Hysteroscopy is the endoscopic visualization of the uterine cavity and the endocervical canal. These areas were inaccessible to the human eye before the discovery of the hysteroscope. Since centuries dilatation and curettage (D\&C) was the only procedure performed for various menstrual disorders as a diagnostic and therapeutic measure and unnecessary hysterectomies were performed as D\&C was ineffective in diagnosing conditions like uterine polyps, endometrial lesions and intra-uterine synechiae. At present hysteroscopy not only leads to a quick, safe, and accurate diagnosis but also plays a curative role in cases of fibroid polyp, intra-uterine adhesions and misplaced intrauterine contraceptive device (IUCD) [1].

This study was undertaken to ascertain the accuracy of hysteroscopy in cases of menstrual disorders.

\section{Material and Methods}

This study is a presentation of all diagnostic hysteroscopies performed from Jan 92 to Dec 93 by the authors at Command Hospital Southern Command and Sonawane Maternity Hospital, Pune.

One hundred and twenty patients with menstrual disorders were subjected to hysteroscopic examination. The procedure was carried out under either paracervical block or general anaesthesia. $\mathrm{K}-\mathrm{Y}$ sterilized lubricating jelly (Ethnor) or $5 \%$ glucose was used as a uterine distending medium. After introduction of a $7 \mathrm{~mm}$ rigid Storz hysteroscope, the whole uterine cavity was visualized. Tubal ostia, endometrium, internal os, and cervical canal were examined for any pathological lesion. Routine D\&C procedure was also performed after each hysteroscopy and endometrium was sent for histology.

\section{Results}

Out of 120 cases $5(4.2 \%)$ were between 20 25 years of age, $10(8.4 \%)$ between $26-30$ years, $25(20.8 \%)$ between $31-35$ years, $35(29.1 \%)$ between $36-40$ years and $45(37.5 \%)$ were 41 years and above. Thus nearly two third of the total patients were 36 years and above.

As regards the types of menstrual disorders, 70

-Classified Specialist (Obst \& Gynae), Military Hospital, Shillong; +Consultant (Obst \& Gynae) \& Commandant, Base Hospital Delhi Cantt - 10; \#Senior Adviser (Obst \& Gynae), 166 Military Hospital, C/o 56 APO. 
patients (58\%) complained of menorrhagia, 7 patients $(6 \%)$ metrorrhagia, 14 patients $(12 \%)$ polymenorrhoea, 6 patients $(5 \%)$ polymenorrhagia, and 23 patients $(19 \%)$ were that of perimenopausal bleeding.

The distension medium used in 90 patients was $\mathrm{K}-\mathrm{Y}$ jelly, while in 30 cases (25\%) 5 percent dextrose was used. The time taken for hysteroscopic procedure varied between 7 minutes to 12 minutes.

On hysteroscopy, out of 70 cases of menorrhagia 6 were diagnosed as endometrial polyp, 4 placental polyp, 6 submucous fibroid, 12 endometrial hyperplasia, 2 cases of uterine synechiae, while in $\mathbf{4 0}$ cases the endometrium was normal. Some of the lesions seen on hysteroscopy can be seen in Fig. 1, 2 and 3. Similarly in 7 cases of metrorrhagia, an underlying cause could be seen in 6 cases $(85.7 \%)$ while in cases of polymenor- rhoea and polymenorrhagia, detection of definitive pathology on hysteroscopy was possible in 6 cases $(30 \%)$ out of 20 . In case of perimenopausal bleeding, hysteroscopy could pick up pathology in 16 cases $(69.5 \%)$ out of the total 23 cases (Table 1).

On histopathological examination, 63 cases (52.5\%) showed proliferative endometrium, 14 cases $(11.7 \%)$ secretory endometrium, 3 cases (2.5\%) atrophic endometrium, 31 cases $(25.8 \%)$ endometrial hyperplasia (cystic type) and 9 cases (7.5\%) showed chronic endometritis. One of the cases of chronic endometritis was of tuberculous origin (Table 2).

There was no post-operative complication in this series except 10 cases (83.\%) who complained of mild abdominal pain and discomfort for the first 24 hours, and which was relieved with Brufen tablet.

TABLE 1

Hysteroscopic findings

\begin{tabular}{|c|c|c|c|c|c|c|c|}
\hline \multirow{2}{*}{ Symptoms } & \multirow{2}{*}{$\begin{array}{l}\text { Total } \\
\text { cases }\end{array}$} & \multicolumn{5}{|c|}{ Hysteroscopic findings } & \multirow[b]{2}{*}{$\begin{array}{c}\text { Normal } \\
\text { endometrial } \\
\text { cavity }\end{array}$} \\
\hline & & $\begin{array}{c}\text { Endometrial } \\
\text { polyp }\end{array}$ & $\begin{array}{l}\text { Placental- } \\
\text { polyp }\end{array}$ & $\begin{array}{l}\text { Submucos- } \\
\text { fibroid }\end{array}$ & $\begin{array}{l}\text { Endometrial } \\
\text { hyperplasia- }\end{array}$ & $\begin{array}{l}\text { Uterine } \\
\text { synechiae }\end{array}$ & \\
\hline Menorrhagia & 70 & 6 & 4 & 6 & 12 & 2 & 40 \\
\hline Metrorrhagia & 07 & 2 & 4 & - & 一 & - & 01 \\
\hline Polymenorrhoea & 14 & 1 & - & - & 01 & - & 12 \\
\hline Polymenorrhagia & 06 & 2 & - & 一 & 02 & - & 02 \\
\hline \multirow[t]{2}{*}{$\begin{array}{l}\text { Perimenopausal } \\
\text { bleeding }\end{array}$} & 23 & 8 & - & - & 08 & - & 02 \\
\hline & 120 & 19 & 8 & 6 & 23 & 2 & 62 \\
\hline
\end{tabular}

TABLE 2

Histologic findings

\begin{tabular}{lcccccc}
\hline Symptoms & Total & \multicolumn{5}{c}{ Histologic findings } \\
\cline { 5 - 7 } & cases & $\begin{array}{l}\text { Proliferative } \\
\text { endometrium }\end{array}$ & $\begin{array}{c}\text { Secretory } \\
\text { endometrium }\end{array}$ & $\begin{array}{c}\text { Atrophic } \\
\text { endometrium }\end{array}$ & $\begin{array}{c}\text { Cystic } \\
\text { hyperplasia }\end{array}$ & $\begin{array}{c}\text { Chronic } \\
\text { endometritis }\end{array}$ \\
\hline Menorrhagia & 70 & 42 & 10 & - & 12 & $6(1 \mathrm{~TB})$ \\
Metrorrhagia & 07 & 05 & - & 1 & 01 & - \\
Polymenonhoea & 14 & 06 & 02 & - & 06 & - \\
Polymenorrhagia & 06 & 02 & - & - & 03 & 1 \\
$\begin{array}{l}\text { Perimenopausal } \\
\text { bleeding }\end{array}$ & 23 & 08 & 02 & 2 & 09 & 2 \\
\hline & 120 & 63 & 14 & 3 & 31 & 9 \\
\hline
\end{tabular}




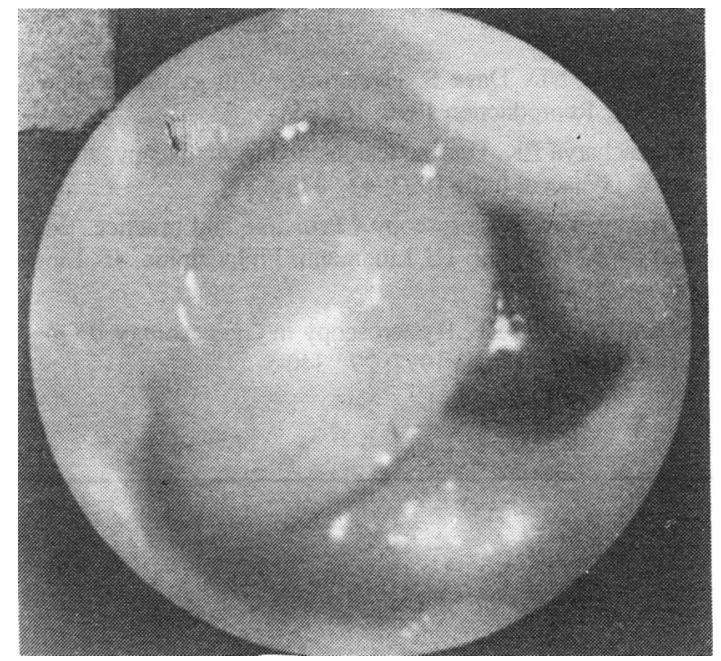

Fig. 1: Benign mucous polyp

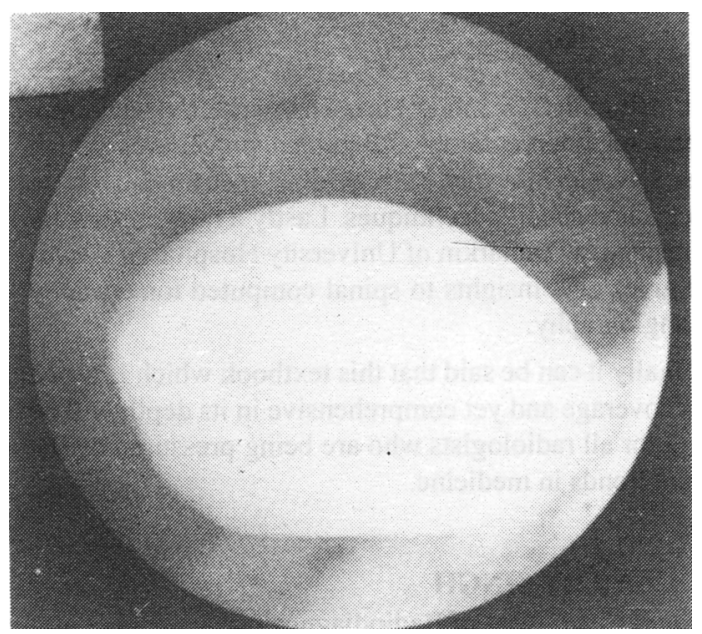

Fig. 2: Submucous fibroid

\section{Discussion}

When most of the endometrial cavity is affected by a lesion it can easily be curetted out and the histology of a sample will be representative of the lesion. However in case of focal lesions curretting may not be reliable as the lesion may be missed on curettage and may be misleading on histological examination. To diagnose a lesion early and to get best prognosis, particularly in cases of menstrual disorders, the ability to observe hysteroscopically the entire endometrium provides valuable information for correct diagnosis and early treatment.

The results of this study correlate well with pre-

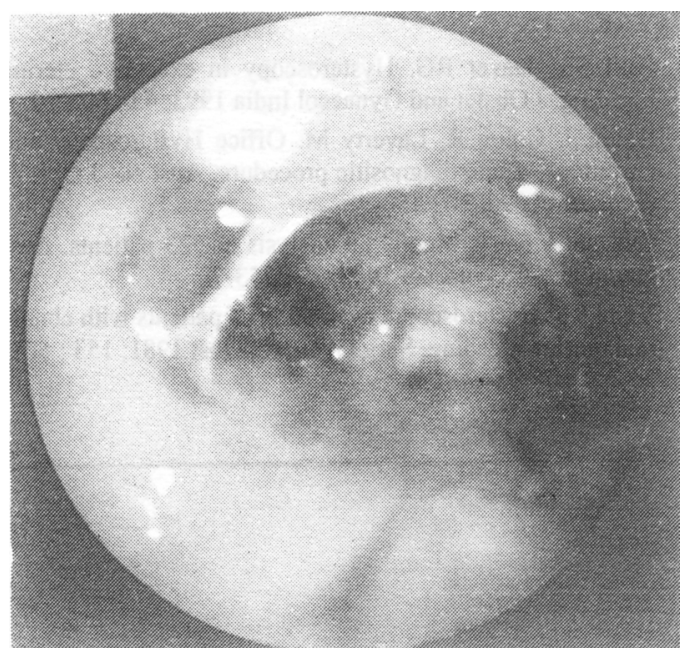

Fig. 3: Intrauterine synechiae

vious hysteroscopic study in patients with abnormal uterine bleeding [1]. The advantage of performing a biopsy under direct vision with hysteroscope rather than blind curettage has been amply demonstrated, particularly in patients with focal lesions and endometrial polyps [2-4]. There were only two cases $(1.70 \%)$ of uterine synechiae in our series, while 5.6 percent cases were reported by Motashaw, 4 percent by Bhattacharya, 3 percent by Wamstaker, and 2 percent by Sciarra [5-8]. However the correlation between uterine synechiae and excessive uterine bleeding still remains unexplained.

The accuracy of hysteroscopic diagnosis was reassessed in this study and its superiority over dilatation and curettage was confirmed. Although hysteroscopy increases diagnostic precision in patients with intrauterine lesions it does not totally exclude other traditional methods of evaluation. Rather it complements them and permits a better diagnosis and therapy particularly in menstrual disorders. Apart from visualization of endometrial cavity a hysteroscopic directed biopsy specimen of suspicious lesions should always be obtained for histopathology.

Hysteroscopy used in menstrual disorders may rule out possible lesions viz. - submucous fibroid, endometrial polyp, endometrial hyperplasia, or carcinoma of endometrium and provides a great help in proper management of these cases. 


\section{REFERTNCES}

1. Patil SK, Daver RG. Hysteroscopy in excessive uterine bleeding. J Obstet and Gynaecol India 1993; 43 : 605-10.

2. David J, Colon R, Laverty M. Office Hysteroscopy and currettage, a safe diagnositic procedure. Aust NZ J Obst \& Oynaccol 1990; $30: 150-3$.

3. George F. 'Hysteroscopy an analysis of 523 patients. Aust NZ J Obst \& Gynacol 1989; 29 : 253-7.

4. Valle RF. Hysteroscopic evaluation of patients with abnormal uterine bleeding. Surg Gynaecol Obst 1981; 153 : 521-
5.

5. Motashaw ND, Dave S. Hysteroscopy in gynaecological practice. Reproduction 1990; 161 : 51-5.

6. Bhattacharya BK. Uterine lesions and hysteroscopy. J Obstet \& Gynaecol India 1992; $42: 373-5$.

7. Wamstaker K. Hysteroscopy - Principle and practice. Edited by AM Siegler. HJ Lindmann. Philadelphia, JB Lippincott, 1984; 128.

8. Sciarra JJ, Valle RF. Hysteroscopy in Gynaccology. J Obstet \& Gynacol India 1977; 27 : 340-5. 